\title{
Evaluating a prototype compact thermal energy storage tank using paraffin-based phase change material for domestic hot water production
}

\author{
George Dogkas ${ }^{1}$, John Konstantaras ${ }^{1}$, Maria K. Koukou, ${ }^{1, *}$, Vassilis N. Stathopoulos ${ }^{1}$, \\ Luis Coelho ${ }^{2}$, and Amandio Rebola ${ }^{2}$ \\ ${ }^{1}$ National and Kapodistrian University of Athens, General Department, Energy and Environmental \\ Research Laboratory, 34400 Psachna Campus, Evia, Greece \\ ${ }^{2}$ Polytechnic Institute of Setubal, Portugal
}

\begin{abstract}
A full-scale thermal energy storage system using phase change materials $(\mathrm{PCM})$ is experimentally investigated for solar and geothermal applications. The system consists of a rectangular tank filled with PCM and a staggered fin tube heat exchanger (HE). The system is designed for the production of Domestic Hot Water (DHW) based on the EU Commission Regulation No 814/2013 [1] requirements. The characteristics that are studied are the stored energy density of the system, the heat transfer rate through the HE during the charging and discharging processes, the adequacy of produced hot water amount and the storage efficiency of the tank. The results of the experiments confirmed the potential of the system to meet several prerequisites of a DHW installation and in addition to make the operation of the coupled solar collector or ground heat pump efficient.
\end{abstract}

\section{Introduction}

A considerable amount of energy is consumed for the thermal demands of buildings. One of the biggest building energy consumption is the production of Domestic Hot Water (DHW). In order to reduce the cost for DHW, the low electricity tariffs during night hours or the free solar radiation can be exploited, but to do so the storage of heat is necessary as the demand of DHW usually does not take place when low or free cost energy is available. There are already solar collectors coupled with a water tank which store hot water in the market. However, a novel tank filled with PCM can provide a more compact solution and it can exploit solar energy more efficiently. In addition, it can also be coupled with a ground heat pump in order to utilize the efficiently geothermal conditions at low tariff periods.

Several researchers have tested PCM units for thermal energy storage and a variety of prototypes have been build. Wu et al. have experimentally studied the performance of a solar water heating system with and without PCM [2]. The outcomes of their research were that the system with PCM is superior as it has higher efficiency, shorter heating water duration

*Corresponding author: mkoukou@uoa.gr, m_koukou@otenet.gr 
and it can maintain the outlet water temperature at the desired value for longer time. In addition, the inclusion of PCM makes the system less sensitive to solar radiation fluctuations.

Frazzica et al. have conducted experiments in order to evaluate the impact of PCM macro-capsules addition into a tank full of water for domestic hot water use [3]. The addition of the PCM capsules increased the heat storage capacity of the tank for all the amounts of PCM and for both types of PCM that were tested. Moreover, the amount of hot water that the capsule enhanced water tank can provide is higher than the water tank without PCM.

Najafian et al. have tested an integration of PCM in domestic water tank which is electrically heated instead of solar [4]. For providing hot water during the whole day, the pure water tank has to be heated twice a day, contrary to the PCM-water tank which requires heating only once, resulting to a lower daily electrical energy consumption. Additionally, the losses of the pure water tank are higher than that of the PCM-water tank because the content of the tank in the first case is at higher temperature. Finally, raising the PCM to water ratio, increases the time period in which hot water is available.

El Qarnia has developed a numerical model for the investigation of PCM materials as a storage medium for solar applications [5]. The model simulated the heat exchange between water and PCM in a concentric tube arrangement where a small copper tube with water passed through a larger tube filled with PCM and it was well validated by experiment. Stearic acid with a melt temperature of $58^{\circ} \mathrm{C}$ was calculated by the model to provide a DHW temperature above $40^{\circ} \mathrm{C}$ for about 30 minutes at a water flow rate of $0.6 \mathrm{lt} / \mathrm{min}$, but the inlet temperature was not reported. The lack of fins on the copper tube resulted to low heat exchange rate and thus slow water flow rate.

Considering the HE design, Kabbara et al. have measured longer duration for the discharging than the charging process at their coil-in-tank heat exchanger and they attributed this fact to the lack of natural convection during solidification [6]. This happens because solid PCM is formed around the coil, inhibiting the buoyancy originated natural flow of the residual liquid PCM. They suggested the addition of fins in order to enhance the heat transfer during solidification. In a former study on a similar, but smaller test rig, the importance of buoyancy driven convection was highlighted both by experimental and numerical model outcomes [7]. It was proven that natural convection during charging is an extra heat transfer mechanism. Furthermore, Medrano et al. examined the heat transfer process of five small HEs immersed in PCM and the result was that the compact HE with finned tube exhibits by far the highest average thermal power [8]. So, the selected HE type was a commercial staggered finned tube heat exchanger used in air-conditioning applications.

The scope of the present work is to examine if a latent heat thermal energy storage tank (LHTES) filled with PCM can provide DHW at prescribed mass flow rates when it is connected with a solar collector or a geothermal heat pump. In this investigation, two commercial organic PCMs with nominal melting temperature difference of $5^{\circ} \mathrm{C}$ were tested and their performance is presented and discussed.

\section{Experimental procedure}

In order to investigate the performance of the DHW LHTES system, a thermal energy storage tank with a HE immersed in PCM was designed and constructed. The system could operate in such way as to reproduce real conditions when it would be connected with a solar collector and a ground coupled heat pump [9]. 


\subsection{Experimental set-up}

The experimental set-up was designed and developed for the investigation of melting and solidification processes when applying different PCMs for various heat transfer fluid (HTF) flow rates. The assembly comprises the plastic tank, the staggered HE, the PCM, hot and cold water buffer tanks, an air-to-water chiller, all the necessary piping, valves and circulating pumps, thermocouples and flowmeters. The entire experimental rig is depicted in Fig. 1.

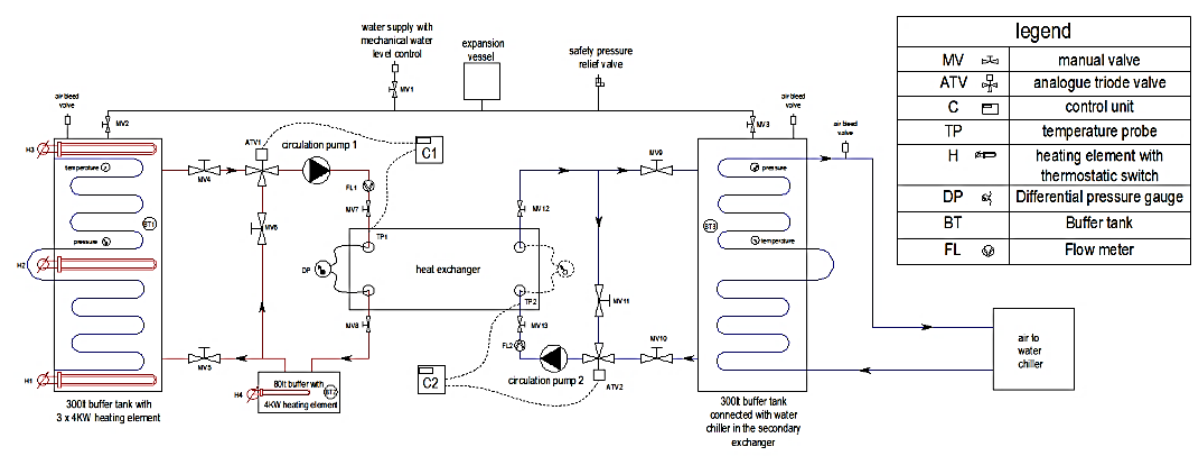

Fig. 1 Hydraulic scheme of the DHW LHTES experimental rig.

The tank is made of polypropylene and it is well insulated with $8 \mathrm{~cm}$ thick polyurethane (Fig. 2). The internal dimensions of the tank are $1220 \times 840 \times 300$ ( $\mathrm{L} \times \mathrm{H} \mathrm{x} \mathrm{W})$. The HE is positioned in the tank. It consists of 12 circuits in parallel, $6 \mathrm{~m}$ long each for solar charging and for ground coupled heat pump charging and 4 circuits in parallel, $18 \mathrm{~m}$ long each for providing DHW. Technical data about the HE are provided in Table 1 and photographs in Fig. 2.

Table 1. Heat exchanger design.

\begin{tabular}{|c|c|}
\hline Number of tubes & 144 \\
\hline Inner tube diameter $(\mathrm{mm})$ & 7.925 \\
\hline Outer tube diameter $(\mathrm{mm})$ & 9.525 \\
\hline Tube material & Copper \\
\hline Fins material & Aluminium \\
\hline Fin thickness $(\mathrm{mm})$ & 0.3 \\
\hline Fin height $(\mathrm{mm})$ & 600 \\
\hline Fin width $(\mathrm{mm})$ & 256 \\
\hline Fin spacing $(\mathrm{mm})$ & 5 \\
\hline
\end{tabular}

Hot water was supplied by a 300 lt boiler with $12 \mathrm{KW}$ electric heaters and cold water was supplied by a $300 \mathrm{lt}$ water buffer tank connected to an air-to-water chiller with $8.1 \mathrm{~kW}$ cooling capacity. There are also two circulation pumps (Grundfos ${ }^{\circledR}$ ALPHA 2 32-60 180 inverter), two three-way temperature control valves $\left(\right.$ Belimo ${ }^{\circledR}$ LR24A-SR valve and Vector ${ }^{\circledR}$ TCI-W11 controller), two analog flowmeters (with measuring range of $4-1000 \mathrm{lt} / \mathrm{min}$ ), "T" type thermocouples and a data logger (National instrument ${ }^{\circledR} \mathrm{cDAq}-9174$ base, $2 \times 921316 \mathrm{ch}$ cards, LabVIEW ${ }^{\circledR}$ data logger). The accuracy of the thermocouples is $+/-0.5^{\circ} \mathrm{C}$. The rig allows for easy replacement of the test PCM tanks. Water is the selected HTF. To analyse HE thermal performance during the charging and discharging process, temperature measurements are performed on HTF inlet and outlet temperature and also within the PCM 
volume. For the PCM temperature measurements, 27 thermocouples were positioned on a grid pattern covering the entire PCM volume.
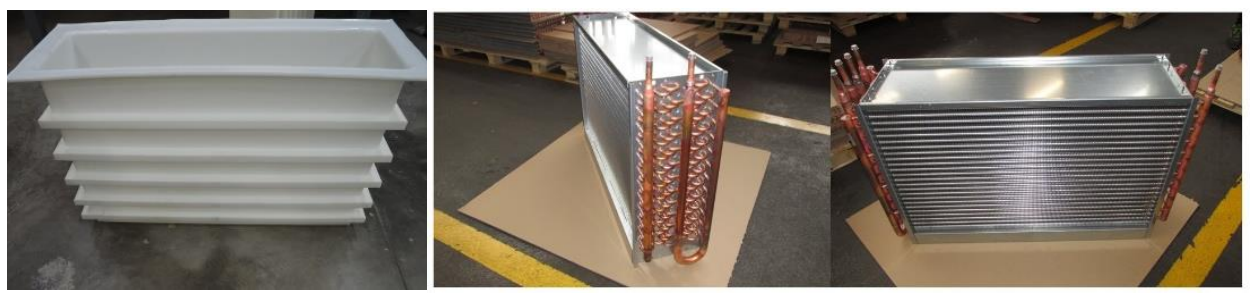

Fig. 2. The tank without insulation (left) and photographs of the heat exchanger (middle- right).

\subsection{PCMs investigated}

The selection of the PCMs used, is an important parameter regarding the design of a LHTES as the amount of energy that may be recovered and the ability to fully charge the system is directly linked to the nature of the material. The selection of PCM in this work is based on the consideration of low temperature solar and geothermal thermal applications [9]. The DHW storage system is designed to store heat between $55-65^{\circ} \mathrm{C}$. The materials tested are commercial products of PCM PRODUCTS Ltd ${ }^{\circledR}[10]$ and their detailed thermal and physical properties provided by the company are summarised in Table 2.

Table 2. Thermal and physical properties of organic paraffins according to the manufacturer [10].

\begin{tabular}{|l|c|c|c|c|}
\hline & \multicolumn{2}{|c|}{$\begin{array}{c}\text { A53 } \\
\text { Refined paraffin wax } \\
\text { blend }\end{array}$} & \multicolumn{2}{|c|}{$\begin{array}{c}\text { A58H } \\
\text { Naturally derived fatty } \\
\text { alcohol blend }\end{array}$} \\
\hline & \multicolumn{2}{|c|}{ Solid } & Liquid & \multicolumn{2}{|c|}{ Solid } & Liquid \\
\hline Nominal phase change temperature $\left({ }^{\circ} \mathrm{C}\right)$ & \multicolumn{2}{|c|}{53} & \multicolumn{2}{|c|}{58} \\
\hline Density $\left(\mathrm{kg} / \mathrm{m}^{3}\right)$ & 839 & 772 & 816 & 790 \\
\hline Thermal conductivity $(\mathrm{W} / \mathrm{m} \cdot \mathrm{K})$ & 0.22 & 0.22 & 0.22 & 0.22 \\
\hline Specific $(\mathrm{J} / \mathrm{kg} \cdot \mathrm{K})$ & 2400 & 1800 & 2400 & 1800 \\
\hline Latent heat $(\mathrm{kJ} / \mathrm{kg})$ & 237.5 & 237.5 & 284.5 & 284.5 \\
\hline Mass $(\mathrm{kg})$ & \multicolumn{2}{|c|}{94.24} & \multicolumn{3}{|c|}{93.95} \\
\hline
\end{tabular}

\subsection{Experimental procedure}

Liquid PCM is poured in the tank and fills the space around the HE. Then, with the lid of the tank open, it is left to cool up to room temperature. Then, hot HTF is supplied from hot water buffer and melts the PCM. This is the charging process. Immediately after the charging process, the hot water supply stops and cold water from the air-to-water chiller begins to circulate. The stored heat inside the PCM is now transferred to the cold water and this is the discharging process. Two values of HTF flow rates were used in order to simulate the real operation with either solar or heat pump charging and are reported in Table 3. For the solar operation, the selected flow rate and low water temperature increases the efficiency of the solar collector as described by its characteristic equation according to EN12975 standard [11]. Finally, the discharging water flow rate was based upon the EU Commission Regulation No 814/2013 which defines the nominal tap water temperature and flow rate which can fulfil 
the needs of a family domestic building (4 persons) [1]. According to the European Regulation for DHW storage tanks, the water temperature delivered to the user must be above $40{ }^{\circ} \mathrm{C}$, regardless of the inlet water temperature at the storage tank. In addition, the volumetric flow rate is defined at $8 \mathrm{lt} / \mathrm{min}$ for shower and $12 \mathrm{lt} / \mathrm{min}$ for bath. The inlet temperature of the water was set at $5^{\circ} \mathrm{C}$ in order to simulate even the coldest climate conditions. Most heat pumps on the market can't produce water at higher temperature and at the same time the efficiency of solar collectors decreases as water temperature at the outlet increases. The operation temperature was selected to be within the 57.5 and $63.5^{\circ} \mathrm{C}$ range, this being the expected real operating conditions for charging by the heat pump and the solar collectors. For the heat pump charging the inlet temperature was defined 5 degrees above the PCMs nominal phase change temperature.

Table 3. Conditions for charging and discharging.

\begin{tabular}{|l|c|c|c|c|}
\hline \multirow{2}{*}{} & \multicolumn{2}{|c|}{ Solar } & \multicolumn{2}{c|}{ Heat Pump } \\
\cline { 2 - 5 } & A53 & A58H & A53 & A58H \\
\hline Initial PCM temperature before charging $\left({ }^{\circ} \mathrm{C}\right)$ & 36 & 36 & 36 & 36 \\
\hline Charging temperature $\left({ }^{\circ} \mathrm{C}\right)$ & 57.5 & 63.5 & 58.0 & 63.0 \\
\hline Charging flow $(\mathrm{lt} / \mathrm{min})$ & 17.7 & 17.7 & 23 & 23 \\
\hline Discharging temperature $\left({ }^{\circ} \mathrm{C}\right)$ & 5.0 & 5.0 & 5.0 & 5.0 \\
\hline Discharging flow $(\mathrm{lt} / \mathrm{min})$ & 12.0 & 12.0 & 8.0 & 8.0 \\
\hline
\end{tabular}

\section{Results and discussion}

During the charging process, the temperature of the water at the outlet of the PCM tank was measured and the corresponding temporal evolution is depicted in Fig. 3. For higher water flow, the outlet temperature reaches its maximum faster for both materials. Moreover, after about 2 hours both materials have reached the maximum value which is enough time to accomplish a full solar charge. It should be mentioned that common ground source heat pumps have difficulties providing temperatures above $60^{\circ} \mathrm{C}$ limiting the use of $\mathrm{A} 58 \mathrm{H}$ and for that type of device, A53 is a more appropriate selection.

In Fig. 4 the calculated heat transfer rate versus stored energy based on the experimental measurements is plotted for the four cases. Regression lines are also depicted having the corresponding colour of the data. The heat transfer rate is calculated by equation 1 , where $\dot{Q}$ is the heat transfer rate $(\mathrm{W}), \dot{m}$ is the water flow rate $(\mathrm{kg} / \mathrm{s}), c p$ is the heat capacity of water $(\mathrm{J} / \mathrm{kgK}), T_{\text {in }}$ is the inlet water temperature $(\mathrm{K})$ and $T_{\text {out }}$ is the outlet water temperature $(\mathrm{K}) . \mathrm{It}$ can be seen that the heat transfer rate for more than the half capacity of the tank is above $5 \mathrm{~kW}$ which is a large rate, making the operation of the solar and the geothermal systems efficient.

$$
\dot{Q}=\dot{m} \cdot c p \cdot\left(T_{\text {in }}-T_{\text {out }}\right)
$$

When the system is reaching its full capacity, the heat transfer rate decreases and the decrease is more intense for A53. Furthermore, the slower flow rate yields slightly higher heat transfer rate for both materials. When the heat transfer rate is low, problems related to the operation of the ground heat pump and the solar collector emerge. At these conditions, the heat produced by the solar panels cannot be fully utilized. Moreover, for ground heat pumps with no inverter, the operation will be discontinued leading to repeated start-stops which reduce the efficiency and the lifespan of the device. 


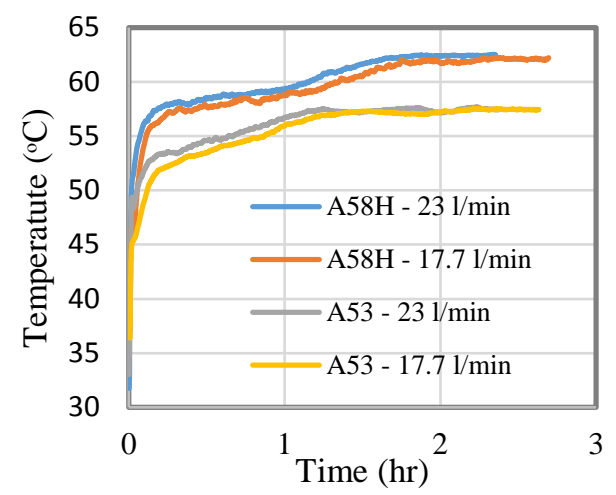

Fig. 3. Water outlet temperature temporal evolution, for solar and ground heat pump charging for both materials.

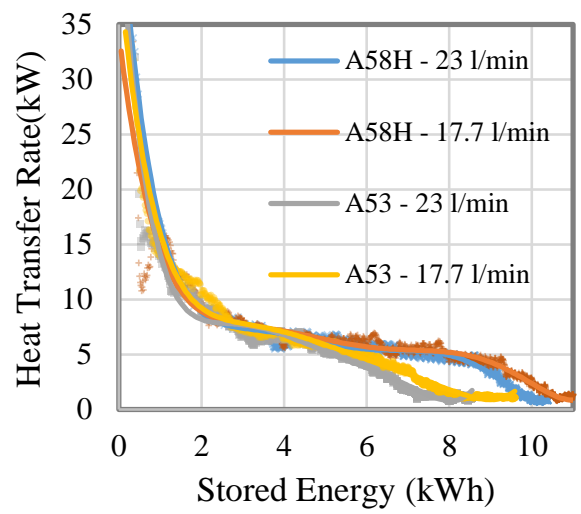

Fig. 4. Heat transfer rate during solar and geothermal charging conditions as a function of stored energy.

The high thermal resistance of the paraffin PCMs examined has an impact on the heat transfer rate towards water. Although, the heat transfer area is increased vastly with the addition of fins and although the discharge water tube was designed to be very long, an increase of the discharge flow rate from 8 to $12 \mathrm{lt} / \mathrm{min}$ resulted to decrease the available time to heat the water.

In Fig. 5 it is evident that the amount of heat that was delivered to the water is less when the flow rate is high for both materials. However, A58H delivers more heat to the water than A53 for all flow rate values. According to the manufacturer (Table 2), A58H exhibits higher volumetric latent heat value $\left(\mathrm{kJ} / \mathrm{m}^{3}\right)$ than $\mathrm{A} 53$, but also it is charged with higher inlet temperature. These two facts justify the higher delivered heat by $\mathrm{A} 58 \mathrm{H}$.

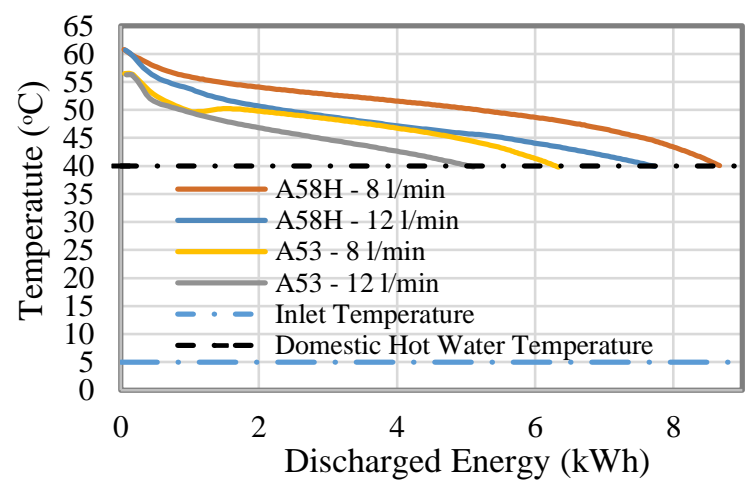

Fig. 5. Outlet and inlet temperature of the water for both PCMs and flow rates.

During discharging, the magnitude of the heat transfer rate is larger than during charging and it also decreases as the remaining heat in the tank is drained. The experimental heat transfer discharging rates are shown in Fig. 6 together with the related regression lines. The heat transfer ability of $\mathrm{A} 58 \mathrm{H}$ is greater than that of A53 for both water consumption rates. From Fig. 6 it is also clear that the heat transfer rate and the amount of heat discharged are inverse quantities. Consequently, when the hot water consumption rate is low, then the hot water production will extend for longer time and more heat will be delivered to heat the water. 
The duration of the discharging process (up to the time when outlet water temperature drops to $40^{\circ} \mathrm{C}$ ) for $\mathrm{A} 53$ is $15.3 \mathrm{~min}$ at slow-flow and $8.8 \mathrm{~min}$ at fast-flow and for $\mathrm{A} 58 \mathrm{H}$ is $20.6 \mathrm{~min}$ at slow-flow and $12.8 \mathrm{~min}$ at fast-flow. The corresponding volume of hot water with temperature above $40^{\circ} \mathrm{C}$ provided by the thermal system is $122 \mathrm{~L}$ at slow-flow and $106 \mathrm{~L}$ at fast-flow for A53 and $164 \mathrm{~L}$ at slow-flow and $153 \mathrm{~L}$ at fast-flow for $\mathrm{A} 58 \mathrm{H}$.

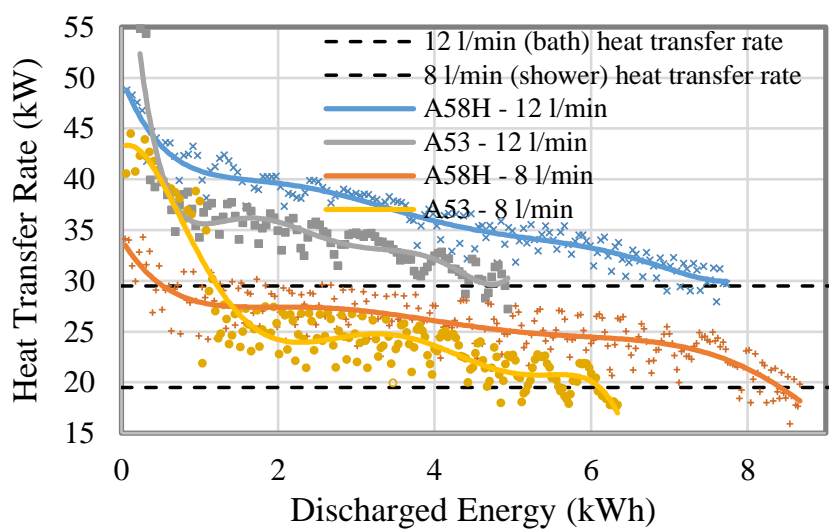

Fig. 6. Heat transfer rates as a function of the discharged energy with parameter the hot water consumption rate.

Considering the ratio of the discharging to charging energy, $\mathrm{A} 58 \mathrm{H}$ has higher ratio than A53. In particular, A58H gives back $73 \%$ of the energy used to charge it for the fast flow and $79 \%$ for the slow flow. The percentage for A53 is 59\% and 64\% respectively. Both materials can return more energy when the HTF flow rate is slow, although the losses during slow flows are higher because the tank losses heat towards the surroundings for a larger time period compared to a faster process. Although the above ratios appear to be low, it is a fact that an amount of energy remains in the tank. This energy can be extracted if the system is left to reach a thermal equilibrium and then drained again. Given the total volume of the storage system with the insulation of the tank applied, the energy density during discharging is $8.89 \mathrm{Wh} / \mathrm{L}$ at slow-flow and $7.13 \mathrm{Wh} / \mathrm{L}$ at fast-flow for $\mathrm{A} 53$, while for $\mathrm{A} 58 \mathrm{H}$ the corresponding values are $12.44 \mathrm{Wh} / \mathrm{L}$ at slow-flow and $10.92 \mathrm{Wh} / \mathrm{L}$ at fast-flow.

\section{Conclusions}

A LHTES system for DHW applications was experimentally tested for operation coupled with solar collectors or ground heat pump. Two different commercial paraffin PCMs were examined. The results from the investigation are summarized below:

- The system can be charged after about 2 hours of constant temperature water feed, a period short enough for charging through solar radiation. For faster charging, higher feed rates are required according to the experimental results.

- All cases have similar heat transfer rate up to $4.8 \mathrm{kWh}$ of heat provided by the HTF which is about half the capacity of the tank. Then, A53 rate decreases more than A58H, making the operation of the solar or heat pump system inefficient. Moreover, both materials present higher heat transfer rate when they are charged slowly.

- The discharging heat transfer rate is analogue to the hot water consumption rate although the HE has large heat transfer area. On the contrary, the amount of heat delivered to the 
water is inversely analogue to the consumption rate. In all cases, the heat transfer rate is higher during discharging than during charging as expected.

- The produced hot water with temperature above $40^{\circ} \mathrm{C}$ quantity, ranges from 106 to $164 \mathrm{~L}$.

- $\mathrm{A} 58 \mathrm{H}$ can deliver a larger amount of heat before the temperature of the hot water drops to $40^{\circ} \mathrm{C}$ which attributed to its higher volumetric latent heat and charging temperature.

- The percentage of delivered to provided heat is within 59 and $79 \%$ and can be increased further if a second discharge is applied after thermal equilibrium is established.

- Thermal energy storage systems using PCMs do not present danger of appearance of legionella, even with water at around $40^{\circ} \mathrm{C}$, because, since there is no volume of water stored, the production is instantaneous.

The work is supported by TESSe2b project which has received funding from the European Union's Horizon 2020 research and innovation program under grant agreement No 680555.

\section{References}

1. E.U., "implementing Directive 2009/125/EC of the European Parliament and of the Council with regard to ecodesign requirements for water heaters and hot water storage tanks", No 814/2013, Commission Regulation (EU) (2013)

2. W. Wu, S. Dai, Z. Liu, Y. Dou, J. Hua, M. Li, X. Wang, Solar Energy 171, 604-612 (2018)

3. A. Frazzica, M. Manzan, A. Sapienza, A. Freni, G. Toniato, G. Restuccia, Applied Energy 183, 1157-1167 (2016)

4. A. Najafian, F. Haghighat, A. Moreau, Energy and Buildings 106, 59-64 (2015)

5. H. E. Qarnia, Energy Conversion and Management 50, 247-254 (2009)

6. M. Kabbara, D. Groulx, A. Joseph, International Journal of Thermal Sciences 130, 395-405 (2018)

7. M. Koukou, M. Vrachopoulos, N. Tachos, G. Dogkas, K. Lymperis, V. Stathopoulos, Thermal Science and Engineering Progress 7, 87-98 (2018)

8. M. Medrano, M. Yilmaz, M. Nogues, I. Martorell, J. Roca, L. Cabeza, Applied Energy 86, 2047-2055 (2009)

9. Tesse2b project deliverable 8.5: Training material. Available at: http://www.tesse2b.eu/Content/images/tesse2b/Training_Material.pdf

10. P. P. Ltd., "http://www.pcmproducts.net/," PCM Products Ltd., [Online]. Available: http://www.pcmproducts.net/. [Accessed February 2019]

11. EN 12975-2 "Thermal solar systems and components - Solar collectors - Part 2: Test methods" (2006) 